\section{Meloxicam as a Radiation-Protective Agent on Mandibles of Irradiated Rats}

\author{
Mayra Cristina Yamasaki, Yuri Nejaim, Gina Delia Roque-Torres, Deborah \\ Queiroz Freitas
}

Department of Oral Diagnosis, Division of Oral Radiology, Piracicaba Dental School, UNICAMP - Universidade Estadual de Campinas, Piracicaba, SP, Brazil

Correspondence: Mayra Cristina Yamasaki, Av. Limeira, 901, 13414-903 Piracicaba, SP, Brasil. Tel: +55-19-2106-5327. e-mail: mcyamasaki@uol.com.br

\begin{abstract}
This study evaluated the action of ionizing radiation and the possible radioprotective effect of the non-steroidal anti-inflammatory drug meloxicam on the bone physiology of rat mandibles by assessing the alveolar socket healing and bone strength. Forty male Wistar rats were divided in 4 groups $(n=10)$ : control (CG), irradiated (IG), meloxicam (MG), meloxicam irradiated (MIG). A dose of $0.2 \mathrm{mg} / \mathrm{kg}$ meloxicam was administered to MG and MIG. After this, IG and MIG were irradiated with $15 \mathrm{~Gy}$ radiation dose in the mandible. Forty days after the above procedures, the mandibular first molars were extracted and the animals were killed after 15 or 30 days $(n=5)$. Micro-computed tomography and bending test were used to evaluate alveolar socket healing and bone strength, respectively. At 15 days, bone volume, bone volume fraction and trabecular thickness were higher in the CG and MG than in the IG and MIG; and trabecular separation was higher in the IG compared with the others. At 30 days, there was a difference only in trabecular separation, which was higher in IG than in CG and MG, and MIG did not differ from the others. Bone strength was lower in IG compared with CG and MG, and MIG did not differ from the others. In conclusion, the ionizing radiation affected the bone physiology of rat mandibles, delaying the alveolar socket healing and reducing the bone strength. Moreover, the meloxicam had a positive effect on the trabecular separation in alveolar socket healing and on the bone strength.
\end{abstract}

Key Words: ionizing radiation, radiation-protective agents, nonsteroidal anti-inflammatory drugs.

\section{Introduction}

Radiotherapy is an important and traditional therapy in the treatment of head and neck cancer. However, despite ongoing research on new radiotherapy protocols, ionizing radiation invariably has some side effects on normal cells, resulting in acute and delayed oral complications. Acute oral complications generally develop within 90 days after beginning of radiotherapy and the most common are mucositis, dermatitis, taste alterations and dry mouth. Delayed oral complications usually occur after 90 days, and may include chronic xerostomia, difficulties with chewing, swallowing and speaking, fibrosis, trismus, atrophy, as well as increased susceptibility to oral infections, dental caries, periodontal diseases and osteoradionecrosis. These oral complications have a negative impact on the quality of life and must be considered before, during and after radiotherapy $(1,2)$.

Although both the acute and delayed oral complications have the same trigger, their development occurs by different processes. The occurrence of the acute oral complications is related to loss of reproductive integrity and cell death caused directly by ionizing radiation due to the formation of free radicals. Regarding the delayed oral complications, the most recent theory is based on changes in tissue physiology due to a fibroatrophy process induced by ionizing radiation. According to this theory, initially there is non-specific chronic local inflammation in the tissues, leading to necrosis of microvessels and local ischemia, followed by a progressive increase of fibrotic tissue in the region. In the irradiated bone tissue, the result of fibroatrophy process is shown by fibrosis of the marrow spaces and periosteum, along with a reduction in vascularity, which decreases the transport of nutrients and white blood cells. Consequently, the rate of cell death increases, impairing bone remodeling and healing, and the susceptibility to bone infections also increases. The main implication of the different development processes of the oral complications is the fact that when radiotherapy has finished, the acute ones are generally reversible while the delayed ones induce permanent tissue changes (2-4).

In order to mitigate oral complications, many radiationprotective agents have been studied with the aim of reducing the side effects due to radiotherapy on normal cells (5-11). Possible radioprotective effects of non-steroidal anti-inflammatory drugs (NSAIDs) have been researched recently and positive results have been observed $(5,6$, 10). The ionizing radiation used in radiotherapy induces inflammation mediators in normal tissues, especially by activation of cyclooxygenase 2 (Cox-2) and damage may occur (5), thus justifying the research on NSAIDs as radiation-protective agents.

Apart from the consequences of the bone physiology 
changes due to radiotherapy, it is important to research the possible effect of radiation-protective agents on its occurrence. Even though the changes in bone physiology may be related to an inflammatory process of the bone tissues induced by ionizing radiation, the effect of NSAIDs on it has not yet been studied. Therefore, this experimental animal model was proposed in order to evaluate the action of ionizing radiation and the possible radioprotective effect of the NSAID meloxicam on the bone physiology of rat mandibles by assessing the alveolar socket healing and the bone strength.

\section{Material and Methods}

The study protocol was first approved by the Local Ethics Committee on Animal Use. Forty male Wistar rats, 75 days old and weighing around $350 \mathrm{~g}$, were used. The animals were maintained in a room at a controlled temperature and relative humidity, in a light/dark cycle of $12 \mathrm{~h}$, on a standard pelleted rodent diet and water ad libitum.

The animals were randomly divided into 4 experimental groups $(n=10)$ according to meloxicam administration and radiation delivery: control group (CG), without meloxicam administration nor radiation; irradiated group (IG), without meloxicam administration and delivery of radiation; meloxicam group (MG), with meloxicam administration and no radiation; meloxicam irradiated group (MIG), with both meloxicam administration and radiation.

When the animals were 75 days old, they were anaesthetized with a single intramuscular injection of $100 \mathrm{mg} / \mathrm{kg}$ ketamine (Dopalen, Ceva Saúde Animal, Paulínia, SP, Brazil) and $10 \mathrm{mg} / \mathrm{kg}$ xylazine (Rompun, Bayer S.A., São Paulo, SP, Brazil). Then, a single dose of $0.2 \mathrm{mg} / \mathrm{kg}$ meloxicam (Maxicam, Ouro Fino Saúde Animal, Cravinhos, SP, Brazil), as indicated by the manufacturer, was administered intraperitoneally to the animals in the $M G$ and MIG groups. After $1 \mathrm{~h}(5,6)$, the animals in the IG and MIG groups were irradiated with a single $15 \mathrm{~Gy}$ radiation dose in the mandible region using a linear accelerator (Clinic $6 / 100^{\circledR}$, Varian Medical Systems, Palo Alto, CA, USA), with a $100 \mathrm{~cm}$ focal length and a $15 \times 30 \mathrm{~cm}$ collimation field. The animals were positioned with only their head and neck region in the radiation field. Moreover, in order to expose all the animals to the same stimuli and stresses, they were all anaesthetized and distilled water was administered to animals in the CG and IG groups instead of meloxicam.

Forty days after delivery of radiation(12), the animals were anaesthetized again and placed in a holder to keep their mouth open for the bilateral extraction of the first molars, which was done using the Hollenback dental instrument (Duflex ${ }^{\circledR}$, S.S. White, Rio de Janeiro, RJ, Brazil). The animals were killed with an anesthesia overdose, half at 15 days after tooth extraction $(n=5)$ and the other half at 30 days after tooth extraction ( $n=5)$. Gingival healing and the presence of a fistula in the region of the extracted mandibular first molars were evaluated macroscopically before removing the hemimandibles, which were immersed for $72 \mathrm{~h}$ in 10\% buffered formalin and stored in saline solution in a refrigerator until use.

One hemimandible from each animal was used to evaluate alveolar socket healing by micro-computed tomography (micro-CT). Initially, each hemimandible was vertically and centrally positioned in a receptacle with water inside the micro-CT scanner (SkyScan 1174; SkyScan, Kontich, Belgium) and the images were acquired using the following parameters: $50 \mathrm{kV}, 800 \mu \mathrm{A}, 9.47 \mu \mathrm{m}$ pixel size, $0.45^{\circ}$ rotation step, $180^{\circ}$ total rotation, 3 frames and 0.5 $\mathrm{mm}$ aluminum filter. The images were reconstructed using NRecon software (SkyScan) with the following parameters: 700 sections, 1 for smoothing, 5 for ring artefact reduction, $10 \%$ of beam-hardening correction and a histogram with a dynamic range of 0.01-0.12. DataViewer software (SkyScan) was used to adjust the images of the hemimandibles in order to get better positioning of the distal tooth socket of the extracted mandibular first molar. The images were then evaluated using CTAn software (SkyScan) and only the sections including the distal tooth socket of the extracted mandibular first molar were selected to manually delineate the area showing alveolar socket healing. A global threshold ranging from 25 to 65 and from 25 to 80 was established for the hemimandibles of animals killed at 15 and 30 days after tooth extraction, respectively. Then, three-dimensional analysis of the region of interest was performed to examine the features of the trabecular bone microarchitecture, according to Bouxsein et al.(13), like total volume, bone volume, bone volume fraction (bone volume/total volume), trabecular number, trabecular thickness and trabecular separation.

The other hemimandible from each animal was used in the three-point bending test to evaluate bone strength. Each one was placed perpendicularly with the lateral surface on 2 vertical bars of the metal support in a material-testing machine (Instron 4411; Instron, Norwood, MA, USA) with the insert centred between the bars and oriented over the molars of the hemimandible (Fig. 1). The insert deflected the hemimandible at a constant speed of $1 \mathrm{~mm} / \mathrm{min}$ until it fractured and the peak load values representing bone strength were obtained in Newton (N).

Data variables from the micro-CT three-dimensional analysis and the bending test were expressed as mean \pm standard deviation. The results were analyzed and compared by one-way analysis of variance (ANOVA) followed by post hoc comparisons with the Tukey test, using IBM SPSS Statistics 22.0 (IBM Corp, Armonk, NY, USA). Statistical significance was set at $p<0.05$. The null hypothesis under 
consideration was the absence of a significant statistical difference between the experimental groups.

\section{Results}

Macroscopic evaluation of the region of the extracted mandibular first molars before removing the hemimandibles showed complete gingival healing and no fistula in all animals.

The alveolar socket healing was in the intermediate stage at 15 days after tooth extraction and in the final stage, but not complete, at 30 days. Tables 1 and 2 present the data on the features of the trabecular bone microarchitecture of alveolar socket healing for each group. At 15 days after tooth extraction (Fig. 2), total volume $(p=0.308)$ and trabecular number $(p=0.060)$ did not differ statistically between the groups; bone volume $(p<0.001)$, bone volume fraction $(p<0.001)$ and trabecular thickness $(p<0.001)$ were significantly higher in the CG and $\mathrm{MG}$ groups than in the IG and MIG groups; trabecular separation $(p<0.001)$ was significantly higher in the IG group in comparison with the other groups. At 30 days after tooth extraction (Fig. 2), there was no statistical difference among the groups concerning total volume $(p=0.940)$, bone volume $(p=0.943)$, bone volume fraction $(p=0.513)$, trabecular number $(p=0.204)$ and trabecular thickness $(p=0.299)$. However, trabecular separation $(p=0.019)$ was significantly higher in the IG group than in the $C G$ and MG groups and the MIG group did not differ statistically from the others.

Regarding hemimandible bone strength, as presented in Table 3, the values for the IG group were significantly lower compared with the $\mathrm{CG}$ and $\mathrm{MG}$ groups $(\mathrm{p}=0.006)$, and the MIG group did not differ statistically from the others.

\section{Discussion}

Changes in bone physiology are one of the oral complications due to radiotherapy, and it may trigger more severe oral complications, like osteoradionecrosis.

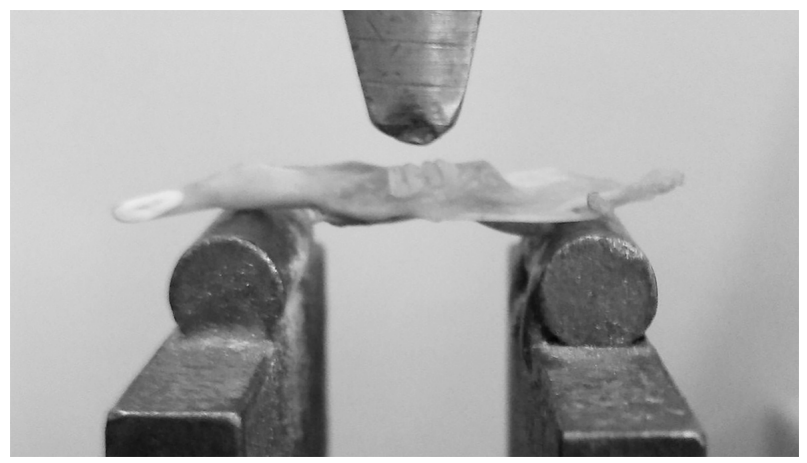

Figure 1. Positioning of the sample for the bending test.
Thus, it is important study it and for this, use of experimental animal models is necessary $(14,15)$. Earlier studies were done to develop an induction model of osteoradionecrosis in animals by causing changes in bone physiology with ionizing radiation(12,14-18); however, none of these studies focused at preventing its occurrence. In addition, although other studies evaluated the possible effects of radiation-protective agents on ionizing radiation damage(5-11), they tested the agents on acute complications and none correlated to delayed complications. Consequently, this study may be considered pioneering in the search for radiation-protective agents relative to extensive changes in irradiated bone.

It is worth mentioning that bone physiology could not be directly evaluated, since it is a dynamic process that refers to how the bone is working. In contrast, there are many methods to evaluate indirectly its response, among which was chosen the assessment of alveolar socket healing and bone strength, which are highly associated to clinical aspects concerning to possible tooth extractions and to bone fractures susceptibility, respectively. Moreover, regarding the evaluation of alveolar socket healing by micro-CT, no values for trabecular bone microarchitecture features were reported in previous studies in relation to trabecular analysis of alveolar socket healing in rats, whether irradiated or not. Thus, the values obtained in this study may be a reference for further studies.

In the present study, as in others $(12,17)$, was chosen to use external irradiation, similar to the standard protocol for head and neck radiotherapy. The region chosen for irradiation was the mandible, because it is more susceptible to osteoradionecrosis than the hind limbs in animals (15); thus, lower radiation doses had to be used because the head and neck region has more radiosensitive tissues and a high radiation dose could induce early mortality of the animals(17). With regard to the fractionate irradiation protocol, although it is recommended in head and neck radiotherapy, its execution is complex in experimental animal models as it requires multiple irradiations and repeated anesthesia, which is undesirable, because it makes reproducing the study more difficult and decreases the probability of the animal survival $(4,14,16)$.

Therefore, a single dose of 15 Gy radiation was used in this study. According to the linear-quadratic model(19) and considering the $\alpha / \beta$ ratio, which quantifies the fractionation radiosensitivity of tissues, equals 2 for bone (12), a single dose of $15 \mathrm{~Gy}$ is equivalent to a total dose of about $64 \mathrm{~Gy}$ in a regimen with multiple 2 Gy fractions as used in the standard protocol for head and neck radiotherapy. In addition, the total dose of $64 \mathrm{~Gy}$ is compatible with the minimum radiation dose (60 Gy) needed to enable the development of 
osteoradionecrosis $(1,3,12)$.

In order to simulate the situation in which a patient must have a tooth extracted sometime after radiotherapy, tooth extraction was performed on the animals, similar to others studies $(14,18,20)$. However, unlike those studies, it was chosen to perform it 40 days after the animals received irradiation, a period sufficient to reveal histological changes in bone tissue in mandibles of irradiated rats(12), and because tooth extraction is contraindicated during treatment.

Table 1. Mean and standard deviation of trabecular bone microarchitecture data regarding volume analysis for each group

\begin{tabular}{lcccc}
\hline Group & & $\begin{array}{c}\text { Total volume } \\
\left(\mathrm{mm}^{3}\right)\end{array}$ & $\begin{array}{c}\text { Bone volume } \\
\left(\mathrm{mm}^{3}\right)\end{array}$ & $\begin{array}{c}\text { Bone volume } \\
\text { fraction } \\
(\%)\end{array}$ \\
\hline & CG & $1.96 \pm 0.28 \mathrm{a}$ & $1.46 \pm 0.19 \mathrm{a}$ & $75.30 \pm 7.69 \mathrm{a}$ \\
15 & IG & $2.08 \pm 0.11 \mathrm{a}$ & $0.83 \pm 0.17 \mathrm{~b}$ & $40.01 \pm 8.22 \mathrm{~b}$ \\
days & MG & $1.84 \pm 0.22 \mathrm{a}$ & $1.40 \pm 0.18 \mathrm{a}$ & $76.38 \pm 5.40 \mathrm{a}$ \\
& MIG & $2.02 \pm 0.12 \mathrm{a}$ & $0.94 \pm 0.16 \mathrm{~b}$ & $46.98 \pm 9.98 \mathrm{~b}$ \\
& $\mathrm{CG}$ & $1.68 \pm 0.09 \mathrm{a}$ & $1.35 \pm 0.13 \mathrm{a}$ & $80.01 \pm 7.94 \mathrm{a}$ \\
30 & IG & $1.71 \pm 0.25 \mathrm{a}$ & $1.30 \pm 0.21 \mathrm{a}$ & $75.85 \pm 5.67 \mathrm{a}$ \\
days & MG & $1.59 \pm 0.51 \mathrm{a}$ & $1.23 \pm 0.56 \mathrm{a}$ & $75.23 \pm 9.74 \mathrm{a}$ \\
& MIG & $1.64 \pm 0.30 \mathrm{a}$ & $1.34 \pm 0.29 \mathrm{a}$ & $81.40 \pm 6.53 \mathrm{a}$ \\
\hline
\end{tabular}

Control group (CG); irradiated group (IG); meloxicam group (MG); meloxicam irradiated group (MIG). Means followed by different letters in the same column are significantly different, according to ANOVA and the Tukey test.
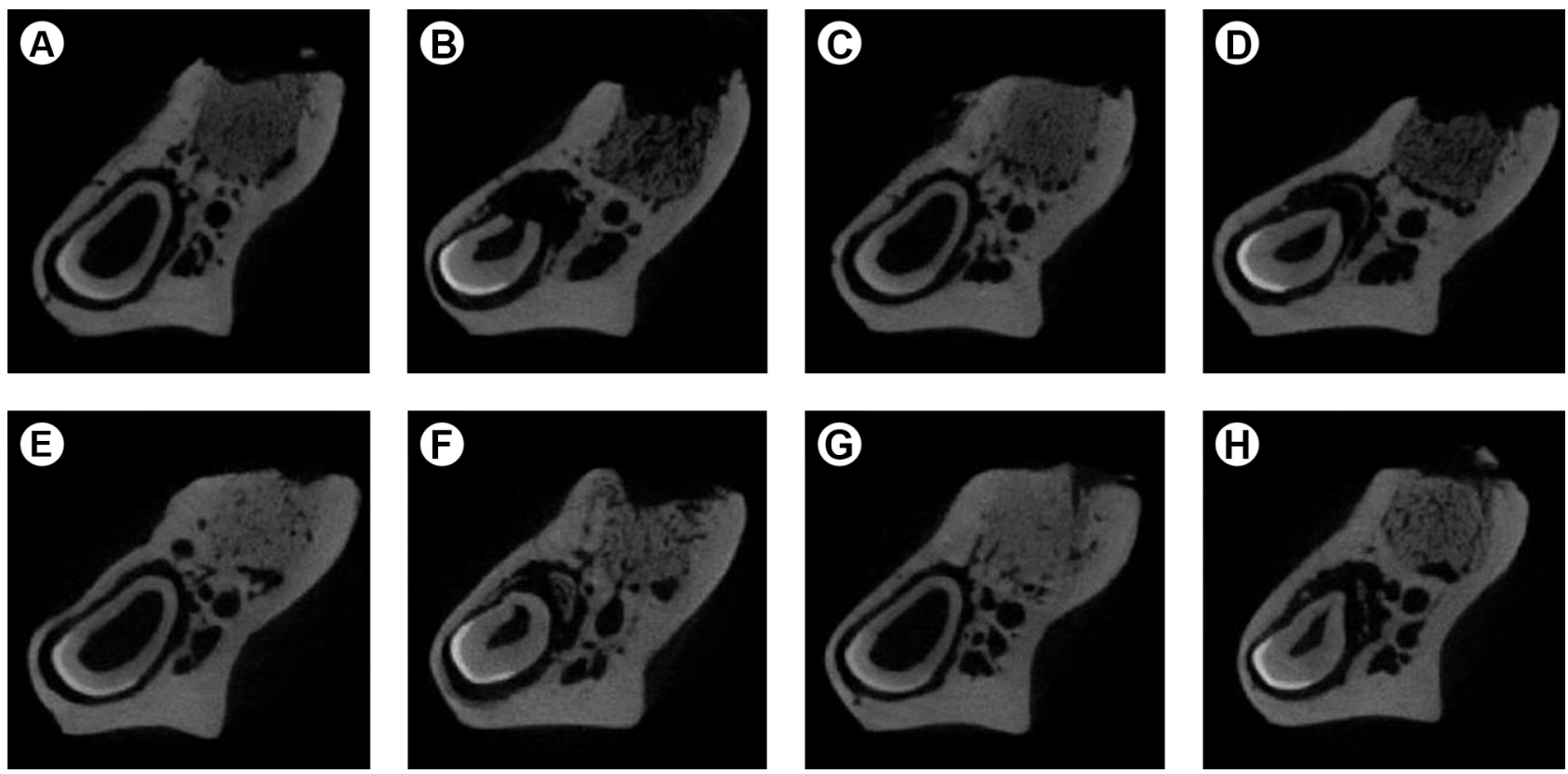

The macroscopic evaluation in the present study showed complete gingival healing and absence of fistula in tooth extraction regions in all animals, suggesting absence of clinical osteoradionecrosis. Lerouxel et al.(17) and Fenner et al.(12) were also unable to induce clinical osteoradionecrosis, but they noted histological changes in irradiated bone tissue. Similarly, this study found that the bone physiology was altered by ionizing radiation, which is evident from the delay in alveolar socket healing at 15 days after tooth extraction and the lower bone strength

Table 2. Mean and standard deviation of trabecular bone microarchitecture data regarding trabecular analysis for each group

\begin{tabular}{lcccc}
\hline Group & & $\begin{array}{c}\text { Trabecular } \\
\text { number } \\
(1 / \mathrm{mm})\end{array}$ & $\begin{array}{c}\text { Trabecular } \\
\text { thickness } \\
(\mathrm{mm})\end{array}$ & $\begin{array}{c}\text { Trabecular } \\
\text { separation } \\
(\mathrm{mm})\end{array}$ \\
\hline & CG & $3.73 \pm 0.22 \mathrm{a}$ & $0.20 \pm 0.03 \mathrm{a}$ & $0.16 \pm 0.05 \mathrm{a}$ \\
15 & IG & $3.70 \pm 0.43 \mathrm{a}$ & $0.11 \pm 0.02 \mathrm{~b}$ & $0.34 \pm 0.04 \mathrm{~b}$ \\
days & MG & $4.43 \pm 0.53 \mathrm{a}$ & $0.17 \pm 0.03 \mathrm{a}$ & $0.16 \pm 0.04 \mathrm{a}$ \\
& MIG & $4.22 \pm 0.59 \mathrm{a}$ & $0.11 \pm 0.01 \mathrm{~b}$ & $0.25 \pm 0.06 \mathrm{a}$ \\
& CG & $5.28 \pm 1.02 \mathrm{a}$ & $0.16 \pm 0.05 \mathrm{a}$ & $0.10 \pm 0.02 \mathrm{a}$ \\
30 & IG & $3.95 \pm 1.28 \mathrm{a}$ & $0.21 \pm 0.05 \mathrm{a}$ & $0.22 \pm 0.11 \mathrm{~b}$ \\
days & MG & $4.91 \pm 1.30 \mathrm{a}$ & $0.17 \pm 0.08 \mathrm{a}$ & $0.11 \pm 0.01 \mathrm{a}$ \\
& MIG & $3.80 \pm 1.32 \mathrm{a}$ & $0.23 \pm 0.06 \mathrm{a}$ & $0.14 \pm 0.04 \mathrm{ab}$ \\
\hline
\end{tabular}

Control group (CG); irradiated group (IG); meloxicam group (MG); meloxicam irradiated group (MIG). Means followed by different letters in the same column are significantly different, according to ANOVA and the Tukey test.

Figure 2. Region of healing in the alveolar socket at 15 days (A-D) and 30 days (E-H) after tooth extraction. A, E: Control group; B, F: irradiated group; C, G: meloxicam group; D, H: meloxicam irradiated group. 
in the IG group compared with the CG group.

The total volume was similar in all groups, demonstrating that the delimited area of alveolar socket healing for the micro-CT three-dimensional analysis was equivalent. It also was observed that alveolar socket healing was clearly delayed by ionizing radiation at 15 days after tooth extraction but not at 30 days, suggesting that it is more affected in the intermediate stage than in the final stage. In the study by Cohen et al. (18), the numerical difference in bone volume fraction between the irradiated group and the control group at 28 days after tooth extraction was lower than the same difference at 21 days after tooth extraction in the study by Tamplen et al. (14), although a higher radiation dose was used in the former study. Considering the disparities in the methodologies, this could support the idea that the final stage of the alveolar socket healing is less influenced by ionizing radiation. Furthermore, the trabecular separation was the only feature of trabecular bone microarchitecture that remained altered in the $\mathrm{Gl}$ group at 30 days after tooth extraction, which suggests that the non-mineralized portion of the alveolar socket in irradiated bone is more affected than the mineralized portion. Regarding the interpretation of the data, it must be emphasized that the trabecular separation is the only one where a lower value is desired in a normal alveolar socket healing, unlike the other parameters of bone trabecular microstructure, which must be higher (13).

Bone strength was reduced in the IG group compared with the CG group. According to Nyaruba et al. (21) and Wernle et al. (22), alterations in bone strength seem to be more related to changes in the trabecular morphology than in the cortical morphology of irradiated bone. Nevertheless, the influence of ionizing radiation on the mechanical properties of bone was not yet fully clarified, as there are conflicting reports in previous studies(11, 21-23). In addition, the micro-CT images (Fig. 2) show changes in the incisor morphology of the animals in the

Table 3. Mean and standard deviation (SD) of bone strength data (N) for each group

\begin{tabular}{lc}
\hline Group & Mean $_{ \pm} \mathrm{SD}$ \\
\hline CG & $92.71 \pm 13.64 \mathrm{a}$ \\
IG & $71.38 \pm 10.07 \mathrm{~b}$ \\
MG & $91.68 \pm 18.32 \mathrm{a}$ \\
MIG & $82.83 \pm 13.03 \mathrm{ab}$ \\
\hline
\end{tabular}

Control group (CG); irradiated group (IG); meloxicam group (MG); meloxicam irradiated group (MIG). Means followed by different letters in the same column are significantly different, according to ANOVA and the Tukey test.
IG group compared with the CG group. This is possibly due to changes of ionizing radiation in the odontogenic region (24), which may have contributed to the decrease in bone strength in the hemimandibles of the irradiated animals.

In search to reduce bone damage due to irradiation, Rocha et al.(8) and Freitas et al. (9) observed a radioprotective effect of sodium selenite on bone healing in rat tibia, and Felice et al. (11) noted radioprotective effects of amifostine on bone strength in rat mandible. However, in this study as in others (5-7), was chosen to evaluate the NSAID meloxicam as a radiationprotective agent. The great advantage of researching the radioprotective effect of NSAIDs is that these drugs are widely studied, even if not for this specific purpose, and their bioavailability, pharmacokinetics and side effects are well known(10). Moreover, it has been suggested that COX-2 inhibition may contribute to control of cancer progression and prevention of metastasis (25). Thus, the administration of NSAIDs could contribute both to mitigate oral complications due to radiotherapy and to aid cancer treatment.

Recently, sodium diclofenac, a classic NSAID, was found to have radioprotective effect on animal survival and on reduction of free radicals and damage to the genetic code of cells after irradiation (10); nevertheless, classic NSAIDs may induce side effects, mainly gastrointestinal ones (7). Furthermore, meloxicam, a COX-2-selective NSAID, has also been shown to have an efficient radioprotective effect on animal survival with administration of a single dose before irradiation (6), and on improvement of hematopoiesis with administration of a single dose before irradiation and of multiple doses after irradiation $(5,6)$. The radioprotective effect on hematopoiesis was not detected only when a single dose of meloxicam was administered after irradiation (7).

It is noteworthy that if meloxicam is used as a radiation-protective agent its aim is to mitigate the changes in the irradiated bone, since the fibroatrophy process induced by ionizing radiation has an initial phase based on a non-specific chronic local inflammation (4). Thus, meloxicam was administrated immediately before the irradiation in order to act in the inflammatory process triggered by ionizing radiation. It is also important to emphasize that a direct action of the meloxicam on the alveolar socket healing is unlikely, because its half-life is around $24 \mathrm{~h}$ and the tooth extraction was performed 40 days after its application. Therefore, the alveolar socket healing is only related to the bone physiologic response.

Meloxicam did not damage trabecular bone microarchitecture and bone strength and it significantly improved trabecular separation at 15 days after tooth extraction. Trabecular separation at 30 days after tooth 
extraction and bone strength were positively influenced by meloxicam. With regard to the clear radioprotective effect observed by Hofer et al. $(5,6)$, the results of the present study fell short of their results, which may be explained by the lower dose of meloxicam used in this study $(0.2 \mathrm{mg} / \mathrm{kg}$ compared with $20 \mathrm{mg} / \mathrm{kg}$ ). This choice was made based on the interest of investigating the influence of the clinically established loading dose. However, as mentioned above, these results may contribute to the idea that the trabecular bone morphology, especially the non-mineralized portion, appears to be more affected by changes in irradiated bone and therefore more favored by meloxicam.

Few studies were found about the possible effect of radiation-protective agents on the bone physiology by assessing the alveolar socket healing and the bone strength, which compromises comparison and validation of the results of this study. With regard to meloxicam, although the results were not ideal, in view of the radioprotective effect demonstrated in previous studies and the improvement in trabecular separation of trabecular bone microarchitecture of alveolar socket healing and in bone strength in this study, the authors still believe that meloxicam may be an - efficient radiation-protective agent in relation to changes in physiology of irradiated bone. Consequently, further studies are required.

In conclusion, the ionizing radiation affected the bone physiology of rat mandibles, delaying the alveolar socket healing and reducing the bone strength. Meloxicam, even though it has not demonstrated a strong radioprotective effect in the bone physiology of rat mandibles, had a positive effect on the trabecular separation of trabecular bone microarchitecture in alveolar socket healing and on the bone strength.

\section{Resumo}

Este estudo avaliou a ação da radiação ionizante e o possivel efeito radioprotetor do anti-inflamatório não esteroide meloxicam na fisiologia óssea de mandibulas de rato por meio da análise da reparação alveolar e da resistência óssea. Quarenta ratos Wistar machos foram divididos em 4 grupos $(n=10)$ : controle $(G C)$, irradiado (GI), meloxicam (GM), meloxicam irradiado (GMI). Administrou-se uma dose única de $0,2 \mathrm{mg} / \mathrm{kg}$ de meloxicam no GM e GMI. Posteriormente, o GI e GMI foram irradiados com dose de 15 Gy na região de mandibula. Decorridos 40 dias dos procedimentos acima, extraiu-se os primeiros molares inferiores dos animais, que foram mortos após 15 e 30 dias $(n=5)$. Utilizou-se a microtomografia computadorizada e o teste de flexão para avaliação da reparação alveolar e da resistência óssea, respectivamente. Aos 15 dias, o volume ósseo, a fração de volume ósseo e a espessura trabecular foram maiores no GC e GM comparados ao GI e GMI; já a separação trabecular foi maior no $\mathrm{Gl}$ em relação aos demais. Aos 30 dias, houve diferença apenas na separação trabecular, que foi maior no Gl em comparação ao GC e GM, não tendo o GMI diferido dos demais. A resistência óssea no $\mathrm{GI}$ foi menor em relação ao $\mathrm{GC}$ e $\mathrm{GM}$, não tendo o GMI diferido dos demais. Concluiu-se que a radiação ionizante afetou a fisiologia óssea das mandibulas de rato, promovendo atraso na reparação alveolar e redução da resistência óssea; além disso, o meloxicam, apresentou efeito positivo na separação trabecular da reparação alveolar e na resistência óssea.

\section{Acknowledgements}

The authors would like to thank the Oncology Center of the Hospital Fornecedores de Cana for the assistance during the experimental phase of the study.

\section{References}

1. Fischer DJ, Epstein JB. Management of patients who have undergone head and neck cancer therapy. Dent Clin North Am 2008;52:39-60.

2. Cabrera AR, Yoo DS, Brizel DM. Contemporary radiotherapy in head and neck cancer: balancing chance for cure with risk for complication. Surg Oncol Clin N Am 2013;22:579-598.

3. Teng MS, Futran ND. Osteoradionecrosis of the mandible. Curr Opin Otolaryngol Head Neck Surg 2005;13:217-221.

4. Jegoux F, Malard O, Goyenvalle E, Aguado E, Daculsi G. Radiation effects on bone healing and reconstruction: interpretation of the literature. Oral Surg Oral Med Oral Pathol Oral Radiol Endod 2010;109:173-184.

5. Hofer M, Pospísil M, Znojil V, Holá J, Vacek A, Weiterová L, et al.. Meloxicam, a cyclooxygenase 2 inhibitor, supports hematopoietic recovery in gamma-irradiated mice. Radiat Res 2006;166:556-560.

6. Hofer M, Pospísil M, Holá J, Vacek A, Streitová D, Znojil V. Inhibition of cyclooxygenase 2 in mice increases production of G-CSF and induces radioprotection. Radiat Res 2008;170:566-571.

7. Hofer M, Pospísil M, Dusek L, Hoferová Z, Weiterová L. Inhibition of cyclooxygenase-2 promotes the stimulatory action of adenosine $A$ receptor agonist on hematopoiesis in sublethally $\nabla$-irradiated mice. Biomed Pharmacother 2011;65:427-431.

8. Rocha ASS, Ramos-Perez FMM, Bóscolo FN, Manzi FR, Chicarelo M, Almeida SM. Effect of sodium selenite on bone repair in tibiae of irradiated rats. Braz Dent J 2009;20:186-190.

9. Freitas DQ, Ramos-Perez FMM, Neves EG, Marques MR, Bóscolo FN, Almeida SM. Radioprotective effect of sodium selenite on bone repair in the tibia of ovariectomized rats. Braz Dent J 2012;23:723-728.

10. Alok A, Adhikari JS, Chaudhury NK. Radioprotective role of clinical drug diclofenac sodium. Mutat Res 2013;755:156-162.

11. Felice PA, Ahsan S, Perosky JE, Deshpande SS, Nelson NS, Donneys A et al.. Prophylactic amifostine preserves the biomechanical properties of irradiated bone in the murine mandible. Plast Reconstr Surg 2014;133:314e-321e.

12. Fenner M, Park J, Schulz N, Amann K, Grabenbauer GG, Fahrig A, et al.. Validation of histologic changes induced by external irradiation in mandibular bone. An experimental animal model. J Craniomaxillofac Surg 2010;38:47-53.

13. Bouxsein ML, Boyd SK, Christiansen BA, Guldberg RE, Jepsen KJ, Müller R. Guidelines for assessment of bone microstructure in rodents using micro-computed tomography. J Bone Miner Res 2010;25:1468-1486.

14. Tamplen M, Trapp K, Nishimura I, Armin B, Steinberg M, Beumer J, et al.. Standardized analysis of mandibular osteoradionecrosis in a rat model. Otolaryngol Head Neck Surg 2011;145:404-410.

15. Damek-Poprawa M, Both S, Wright AC, Maity A, Akintoye SO. Onset of mandible and tibia osteoradionecrosis: a comparative pilot study in the rat. Oral Surg Oral Med Oral Pathol Oral Radiol 2013;115:201-211.

16. Niehoff $P$, Springer IN, Açil $Y$, Lange $A$, Marget $M$, Roldán JC, et al.. HDR brachytherapy irradiation of the jaw - as a new experimental model of radiogenic bone damage. J Craniomaxillofac Surg 2008;36:203-209.

17. Lerouxel E, Moreau A, Bouler JM, Giumelli B, Daculsi G, Weiss P, et al.. Effects of high doses of ionising radiation on bone in rats: a new model for evaluation of bone engineering. Br J Oral Maxillofac Surg 2009;47:602-607.

18. Cohen M, Nishimura I, Tamplen M, Hokugo A, Beumer J, Steinberg ML, et al.. Animal model of radiogenic bone damage to study mandibular osteoradionecrosis. Am J Otolaryngol 2011;32:291-300.

19. Liu L, Bassano DA, Prasad SC, Hahn SS, Chung CT. The linear-quadratic model and fractionated stereotactic radiotherapy. Int J Radiat Oncol Biol Phys 2003;57:827-832.

20. Kurihashi T, Iwata $H$, Nasu M, Yosue T. Experimental study on wound healing of alveolar bone sockets in the rat maxilla after X-ray irradiation. Odontology 2002;90:35-42. 
21. Nyaruba MM, Yamamoto I, Kimura H, Morita R. Bone fragility induced by $\mathrm{x}$-ray irradiation in relation to cortical bone-mineral content. Acta Radiol 1998;39:43-46.

22. Wernle JD, Damron TA, Allen MJ, Mann KA. Local irradiation alters bone morphology and increases bone fragility in a mouse model. J Biomech 2010;43:2738-2746.

23. Tchanque-Fossuo CN, Monson LA, Farberg AS, Donneys A, Deshpande $S S$, Razdolsky ER, et al.. Dose-response effect of human equivalent radiation in the murine mandible: Part II. A biomechanical assessment.
Plast Reconstr Surg 2011;128:480e-487e.

24. Araujo AMM, Gomes CC, Almeida SM, Klamt CB, Novaes PD. Effect of radiotherapy on the eruption rate and morphology of the odontogenic region of rat incisors. Arch Oral Biol 2014;59:1242-1248.

25. Lin DT, Subbaramaiah $K$, Shah JP, Dannenberg AJ, Boyle JO. Cyclooxygenase-2: a novel molecular target for the prevention and treatment of head and neck cancer. Head Neck 2002;24:792-799.

Accepted October 4, 2016 Received February 7, 2017 